\title{
Tingkat Resiliensi Mahasiswa Perantau di Jurusan Bimbingan Konseling Islam Fakultas Ushuludin Adab dan Dakwah IAIN Pontianak
}

\author{
Bella Yugi Fazny 1
}

\begin{abstract}
Abstrak
Diketahui 62\% dari seluruh jumlah mahasiswa prodi Bimbingan Konseling Islam (BKI) di Institut Agama Islam Negeri (IAIN) Pontianak adalah mahasiswa perantau. Mahasiswa perantau menjumpai gejolak perbedaan, penyesuaian kultur, serta dinamika baru di lingkungan tempat tinggal dan perguruan tinggi. Hasil wawancara pribadi pada 26 orang mahasiswa perantau secara random di bulan Juli 2019 ditemukan bahwa pada awal masa orientasi mereka banyak mengalami culture shock dan stress yang berdampak pada motivasi belajar, keadaan suasana hati yang berubah-ubah dan jam tidur yang tidak teratur. Resiliensi adalah kemampuan manusia untuk bertahan dan beradaptasi serta kapasitas manusia untuk menghadapi dan memecahkan masalah setelah mengalami kesengsaraan (Grotberg, 1999). Penelitian ini akan mengambarkan bagaimana tingkat resiliensi mahasiswa perantau di prodi BKI IAIN Pontianak. Metode dalam penelitian adalah studi deskriptif kuantitatif melalui analisis instrumen resiliensi. Populasi pada penelitian ini adalah seluruh mahasiswa perantau pada program studi bimbingan konseling Islam FUAD IAIN Pontianak. Teknik pengambilan sampel yang dipergunakan adalah probability sampling dengan metode convenience sampling. Hasil penelitian menunjukkan bahwa sebanyak 74 orang mahasiswa perantau atau sekitar $62 \%$ dari seluruh sampel memiliki nilai total skor terkategori sedang. Selain itu diketahui dari 7 aspek resiliensi mahasiswa perantau, terdapat dua aspek dengan nilai terendah namun dalam jumlah sampel terbanyak yaitu aspek efikasi diri (100\%) dan aspek control terhadap implus (61\%). Hasil analisis tingkat resiliensi berdasarkan kelompok gender, etnis, kelas sosial (pendapatan sebulan), status pernikahan dan tingkat tahun angkatan tidak menunjukkan tingkat perbedaan yang signifikan. Mayoritas pada masing-masing kelompok memiliki tingkat resiliensi yang sedang.

Kata Kunci: resiliensi; mahasiswa; perantau
\end{abstract}

\begin{abstract}
$62 \%$ of the entire number of students Islamic Guidance and Counseling at the IAIN Pontianak is a student nomads. Student nomads encounter much difference, the adjustment of culture, as well as the dynamics of the new in the neighborhood a place to stay and universities. Interview personally at 26 students nomads are random in the month of July 2019 found that in the initial period of orientation they are much experienced culture shock and stress that affects the motivation to learn, the state of the atmosphere of the heart are fickle and hours of sleep are not regular. Resilience is the ability of humans to survive and adapt and the human capacity to face and solve problems after suffering adversity (Grotberg, 1999). This study will illustrate how the level resilience of students nomads in Islamic Guidance and
\end{abstract}

\footnotetext{
${ }^{1}$ Institut Agama Islam Negeri Pontianak, bellayugi07@gmail.com
} 
Counseling at IAIN Pontianak. Methods research in this study of descriptive quantitative through analytical instruments resilience. The population of this research is the whole student nomads in the program of study Islamic guidance counseling IAIN Pontianak. Mechanical taking samples that are used are the probability sampling by the method of convenience sampling. Results of the study show that most 74 student nomads or approximately $62 \%$ of the entire sample has a value of total score categorized being. Besides that, it is known from 7 aspects of resilience of overseas students, there are two aspects with the lowest score but in the highest number of samples, they are aspects of self-efficacy (100\%) and aspects of control over implants (61\%). Results level of resilience by groups of gender, ethnicity, class social (income a month), the status of marriage and the level of force does not show differences are significant. The majority in each group has a moderate level of resilience.

Keywords: resilience, student, nomads

\section{PENDAHULUAN}

Kualitas perguruan tinggi di Indonesia masih belum merata. Menurut kemenristekdikti (Kementerian Riset dan Teknologi Nasional, 2018) kualitas perguruan tinggi yang dimaksud adalah kualitas sumber daya manusia, kelembagaan, kegiatan mahasiswa, penelitian dan pengabdian masyarakat, serta kualitas inovasi. Kualitas perguruan tinggi non vokasi dengan mutu terbaik dapat ditentukan dari hasil sistem peringkat 100 besar klasterisasi yang dikeluarkan oleh kemenristekdikti.

Tidak hanya dengan sistem peringkat, kualitas suatu perguruan tinggi juga ditentukan dari hasil perolehan nilai akreditasinya. Menurut situs Badan Akreditasi Nasional Perguruan Tinggi (BANPT) pada tahun 2019 dari 2.257 total perguruan tinggi di Indonesia hanya 95 perguruan tinggi yang institusinya terakreditasi A. Lebih lanjut ditemukan dari 51 program studi Bimbingan dan Konseling Islam (BKI) di seluruh Indonesia, hanya 5 program studi yang terakreditasi A. Artinya, di seluruh Indonesia hanya tersedia 5 program studi BKI yang sudah diakui kualitasnya sangat baik.

Sistem peringkat dan nilai akreditasi menjadi sumber referensi bagi siswa yang hendak melanjutkan pendidikan ke perguruan tinggi. Terdapat faktor lain yang mempengaruhi siswa dalam memilih program studi di perguruan tinggi, diantaranya berupa; faktor potensi diri, faktor motivasi, faktor ekspetasi masa depan, faktor peluang, faktor lingkungan sosial, faktor situasi dan kondisi, serta faktor institusional (Indriyanti, Siswandari, \& Ivada, 2013). Amaliya (2019) menambahkan faktor biaya pendidikan, citra prodi, fasilitas pendidikan, dan prospek prodi juga memiliki pengaruh positif dan signifikan terhadap keputusan mahasiswa dalam menempuh pendidikan. Hasil survei nasional Tempo (2017) pada 859 orang siswa SMA kelas XII dari 10 kota besar di Indonesia diketahui terdapat 12 pilihan fakultas favorit yang dipilih oleh siswa. Minat pilihan fakultas dan perguruan tinggi yang dituju oleh siswa sangat beragam bahkan tak jarang keluar dari daerah tempat tinggal mereka.

Fenomena mahasiswa yang berasal dari luar kota tempat perguruan tinggi bukan merupakan hal yang baru. Sesuai dengan data survei yang telah dihimpun oleh peneliti di bulan Juni-Juli, mahasiswa aktif pada prodi BKI di Institut Agama Islam Negeri (IAIN) Pontianak diketahui berjumlah 189 orang, dan 117 orang diantaranya berasal dari luar kota Pontianak. Artinya, diketahui $62 \%$ dari seluruh jumlah mahasiswa BKI 
yang aktif di IAIN Pontianak adalah mahasiswa perantau. Mahasiswa aktif tersebut adalah mahasiswa yang terdaftar di rentang tahun angkatan 2015 hingga 2018.

Mahasiswa perantau akan menjumpai gejolak perbedaan, penyesuaian kultur, serta dinamika baru di lingkungan tempat tinggal dan perguruan tinggi. Brouwer (Alisjahbana, Sidharta, \& Brouwer, 1983) mencatat beberapa masalah yang harus diperhatikan oleh calon mahasiswa dalam kaitannya dengan situasi dan status baru yang dihadapi, yaitu: perbedaan cara belajar, perbedaan tempat tinggal, mencari teman baru, dan hal-hal yang berkaitan pergaulan, perubahan relasi, pengaturan waktu, serta nilai-nilai hidup yang didapat di kampus.

Senada dengan itu, hasil wawancara pribadi peneliti pada 26 orang mahasiswa perantau secara random di bulan Juli 2019 ditemukan bahwa pada awal masa orientasi mereka banyak mengalami culture shock dan stress yang berdampak pada motivasi belajar, keadaan suasana hati yang berubahubah dan jam tidur yang tidak teratur. Menurut wawancara pribadi pada 26 orang mahasiswa perantau tersebut, stress mudah timbul karena (1) kesulitan mengatur waktu antara pengerjaan tugas kuliah dengan kegiatan tugas sehari-hari; (2) kesulitan dalam mengelola pendapatan keuangan dengan kebutuhan hidup, serta kebutuhan belajar diperkuliahan; (3) kesulitan dalam memahami bahasa, menyesuaikan temperatur cuaca dan jenis rasa makanan yang tersedia; (4) kesulitan dalam beradaptasi dengan karakter warga lokal; (5) kesulitan bertahan dalam keadaan sakit dan butuh perawatan. Lebih dari itu masalah lain adalah pencapaian fase peralihan dari tugas perkembangannya.

Mahasiswa perantau di IAIN Pontianak memiliki rentang usia mulai dari 18 hingga 24 tahun. Menurut tahapan perkembangan Erikson (Grotberg, 1995), rentang usia 1321 tahun merupakan tahap remaja akhir dengan tugas perkembangan membangun identitas diri. Serta rentang usai 21-39 tahun merupakan tahap dewasa awal dengan tugas perkembangan membangun relasi yang intim. Tugas perkembangan pada usia ini adalah pemantapan pendirian hidup (Yusuf, 2012).

Havighurst (1961) menambahkan bahwa tugas perkembangan adalah tugastugas yang harus diselesaikan individu pada fase-fase atau periode kehidupan tertentu dan apabila berhasil mencapainya, mereka akan bahagia, tetapi sebaliknya apabila mereka gagal akan kecewa dan dicela orang tua atau masyarakat dan perkembangan selanjutnya akan mengalami kesulitan. Maka dari itu mahasiswa perantau hendaknya memiliki kemampuan resiliensi yang tinggi, agar siap menghadapi berbagai kemungkinan permasalahan yang muncul dalam masa rantauannya.

Makna resiliensi menurut Grotberg (1995) adalah kemampuan manusia untuk bertahan dan beradaptasi, serta kapasitas manusia untuk menghadapi dan memecahkan masalah setelah mengalami kesengsaraan. Resiliensi mencakup mekanisme koping dan adaptasi saat individu berhadapan dengan stressor yang beresiko tinggi dan mengalami stress (Hendriani, 2018).

Refleksi diri merupakan elemen penting dalam meningkatkan resiliensi (Wosnitza et al., 2018). Pola pikir mahasiswa memiliki dampak terhadap tingkat resiliensi dalam menghadapi tantangan akademik dan sosial. Hasil penelitian Yeager (2012) menunjukkan mahasiswa yang diajarkan bahwa kemampuan intelektual adalah kualitas yang dapat dikembangkan, cenderung menunjukkan prestasi yang lebih tinggi di seluruh transisi sekolah dan tingkat penyelesaian pekerjaan yang lebih besar. Selanjutnya mahasiswa yang diajarkan bahwa atribut sosial dapat dikembangkan dapat menurunkan agresi dan stres remaja dalam menanggapi viktimisasi atau eksklusi teman sebaya, dan dapat menghasilkan peningkatan kinerja di sekolah.

Berdasarkan pemaparan latar belakang masalah diatas, peneliti tertarik untuk mengambarkan tingkat resiliensi mahasiswa 
perantau di jurusan bimbingan dan konseling Islam di IAIN Pontianak.

\section{METODE PENELITIAN}

Penelitian studi deskriptif ini menggunakan metode pendekatan kuantitatif. Jadi, penelitian ini akan menggambarkan tingkat resiliensi seluruh mahasiswa perantau dengan cara kuantitatif melalui analisis instrumen resiliensi.

Populasi pada penelitian ini adalah seluruh mahasiswa perantau pada program studi bimbingan konseling Islam FUAD IAIN Pontianak. Kategorisasi mahasiswa perantau adalah mahasiswa aktif yang tempat tinggal domisili sebelumnya di luar kota Pontianak. Diketahui jumlah populasi 117 orang mahasiswa perantau. Teknik pengambilan sampel yang dipergunakan dalam penelitian ini adalah probability sampling dengan metode convenience sampling.

Convenience sampling menurut Dörnyei (2007) adalah "Convenience sampling (also known as Haphazard Sampling or Accidental Sampling) is a type of nonprobability or nonrandom sampling where members of the target population that meet certain practical criteria, such as easy accessibility, geographical proximity, availability at a given time, or the willingness to participate are included for the purpose of the study." Jadi, Convenience sampling lebih dikenal sebagai Haphazard Sampling atau Accidental Sampling, sejenis nonrandom sampling yang target anggota populasinya harus memenuhi kriteria tertentu, seperti aksesibilitas mudah, kedekatan letak geografis, ketersediaan waktu tertentu, atau kesediaan untuk berpartisipasi termasuk untuk tujuan belajar. Maka jumlah sampel pada penelitian ini adalah 117 orang seluruh mahasiswa perantau di prodi Bimbingan Konseling Islam (BKI) IAIN Pontianak.

Penelitian ini menggunakan instrumen resiliensi yang dikembangkan oleh Karen Reivich dan Andrew Shatté pada tahun 2003. Instrumen resiliensi tersebut telah dialih bahasakan dan memiliki 7 aspek resiliensi diantaranya regulasi emosi, kontrol terhadap implus, optimisme, kemampuan menganalisis masalah, empati, efikasi diri serta pencapaian diri. Skala pengukuran yang digunakan pada penelitian ini adalah skala likert dengan 4 kategori penilaian yaitu sangat setuju, setuju, tidak setuju, dan sangat tidak setuju.

Uji validitas konstruk instrumen telah dilakukan dengan menggunakan pendapat ahli. Ahli instrumen dalam penelitian ini adalah dosen psikologi IAIN Pontianak bernama Kiki Amalia., M.Psi. Hasil uji validitas konstruk menunjukkan bahwa bahwa item-item instrumen sudah mewakili teori resiliensi dan 7 aspeknya. Instrumen resiliensi diujicobakan pada 40 orang mahasiswa perantau di prodi BKI secara random pemilihan jenis kelamin dan angkatan tahun ajarannya. Kemudian oleh peneliti diuji kembali validitas empiriknya menggunakan analisis product moment.

Selanjutnya, peneliti melakukan uji reliabilitas alfa cronbach's dengan menggunakan SPSS 22.0. Setelah teruji validitas dan reliabilitas instrumen dilakukan, maka instrumen resiliensi sudah layak dan siap untuk dipergunakan sebagai alat pengukuran gambaran pada penelitian ini. Untuk menganalisis tingkat pengkategorian kelompok peneliti menggunakan skala norma menurut Azwar dalam Widhiarso (2010).

\begin{tabular}{|c|c|c|c|c|c|c|}
\hline Kategori & \multicolumn{6}{|c|}{ Rumus } \\
\hline Tinggi & : & $\bar{x}+s d$ & $\leq$ & Skor & $<$ & $\bar{x}+(2 \times s d)$ \\
\hline Sedang & $:$ & $\bar{x}-s d$ & $\leq$ & Skor & $<$ & $\bar{x}+s d$ \\
\hline Rendah & $:$ & $\bar{x}-(2 \times s d)$ & $\leq$ & Skor & $<$ & $\bar{x}-s d$ \\
\hline
\end{tabular}

\footnotetext{
Keterangan:

$\bar{x}$ : rata-rata

$s d:$ standar deviasi
}

Pada penelitian ini, studi pendahuluan yang dilakukan berupa survei wawancara dan studi dokumentasi di bulan Juni-Juli 2019. Penyebaran dan pengisian instrumen resiliensi dilakukan sepanjang bulan Juli 2019.

\section{HASIL PENELITIAN}


Karakteristik sampel mahasiswa perantau pada penelitian ini telah dianalisis lebih mendalam oleh peneliti berdasarkan survei kategori usia, gender, tahun angkatan, etnis suku, status pernikahan, jumlah penghasilan perbulan, sumber penghasilan perbulan, tempat tinggal saat berkuliah di kota Pontianak dan domisili tinggal sebelumnya.

\begin{tabular}{lcc}
\hline \multicolumn{1}{c}{ Usia } & Jumlah & Presentase \\
\hline 18 tahun & 11 orang & $9 \%$ \\
19 tahun & 29 orang & $25 \%$ \\
20 tahun & 23 orang & $20 \%$ \\
21 tahun & 25 orang & $21 \%$ \\
22 tahun & 21 orang & $17 \%$ \\
23 tahun & 5 orang & $4 \%$ \\
24 tahun & 4 orang & $3 \%$ \\
\hline Total & $\mathbf{1 1 7}$ orang & $\mathbf{1 0 0 \%}$ \\
\hline
\end{tabular}

Tabel 2. Karakteristik sampel berdasarkan usia mahasiswa perantau

Berdasarkan tabel 2 rentang usia dari 117 orang mahasiswa perantau pada program studi BKI IAIN Pontianak berkisar antara 18 hingga 24 tahun. Dapat diketahui bahwa mayoritas mahasiswa perantau berusia 19 tahun.

\begin{tabular}{lcc}
\hline \multicolumn{1}{c}{ Gender } & Jumlah & Presentase \\
\hline Laki-laki & 27 orang & $23 \%$ \\
Perempuan & 90 orang & $77 \%$ \\
\hline Total & $\mathbf{1 1 7}$ orang & $\mathbf{1 0 0 \%}$ \\
\hline
\end{tabular}

Tabel 3. Karakteristik sampel berdasarkan gender mahasiswa perantau

Berdasarkan tabel 3 dapat diketahui bahwa mayoritas gender mahasiswa perantau pada penelitian ini adalah perempuan dengan jumlah 90 orang, 77\% dari seluruh total sampel.

\begin{tabular}{lcc}
\hline $\begin{array}{c}\text { Tahun } \\
\text { Angkatan }\end{array}$ & Jumlah & Presentase \\
\hline 2015 & 23 orang & $20 \%$ \\
2016 & 26 orang & $22 \%$ \\
2017 & 29 orang & $25 \%$ \\
2018 & 39 orang & $33 \%$ \\
\hline
\end{tabular}

\begin{tabular}{ccc}
\hline Total & $\mathbf{1 1 7}$ orang & $\mathbf{1 0 0 \%}$ \\
\hline Tabel 4. Karakteristik sampel berdasarkan tahun \\
angkatan
\end{tabular}

Berdasarkan tabel 4 diketahui bahwa sampel penelitian telah terwakilkan antar lintas tahun angkatan mulai dari tahun 2015 hingga 2018 pada program studi BKI IAIN Pontianak.

\begin{tabular}{lcc}
\hline Etnis Suku & Jumlah & Presentase \\
\hline Melayu & 56 orang & $48 \%$ \\
Madura & 23 orang & $20 \%$ \\
Jawa & 22 orang & $19 \%$ \\
Bugis & 5 orang & $4 \%$ \\
Sunda & 5 orang & $4 \%$ \\
Dayak & 3 orang & $3 \%$ \\
Batak & 2 orang & $2 \%$ \\
Betawi & 1 orang & $1 \%$ \\
\hline Total & $\mathbf{1 1 7}$ orang & $\mathbf{1 0 0 \%}$ \\
\hline
\end{tabular}

Tabel 5. Karakteristik sampel berdasarkan etnis suku

Berdasarkan tabel 5 dapat diketahui bahwa mayoritas mahasiswa perantau beretnis melayu.

\begin{tabular}{lcc}
\hline $\begin{array}{c}\text { Status } \\
\text { Pernikahan }\end{array}$ & Jumlah & Presentase \\
\hline Lajang & 108 orang & $92 \%$ \\
Menikah & 9 orang & $8 \%$ \\
\hline Total & $\mathbf{1 1 7}$ orang & $\mathbf{1 0 0 \%}$ \\
\hline Tabel 6. Karakteristik sampel berdasarkan status \\
pernikahan
\end{tabular}

Berdasarkan tabel 6 dapat diketahui bahwa mayoritas status mahasiswa perantau pada penelitian ini adalah lajang atau belum menikah dengan jumlah 108 orang, 92\% dari seluruh total sampel.

\begin{tabular}{lcc}
\hline Penghasilan/bulan & Jumlah & Presentase \\
\hline $\begin{array}{l}\text { Kurang dari } \\
\text { Rp.500.000 }\end{array}$ & 50 orang & $43 \%$ \\
\hline $\begin{array}{l}\text { Rp.500.000- } \\
\text { Rp.1.000.000 }\end{array}$ & 56 orang & $48 \%$ \\
\hline $\begin{array}{l}\text { Rp.1.000.000- } \\
\text { Rp.2.000.000 }\end{array}$ & 7 orang & $6 \%$ \\
\hline
\end{tabular}




\begin{tabular}{lcc}
\hline $\begin{array}{l}\text { Lebih dari } \\
\text { Rp.2.000.000 }\end{array}$ & 4 orang & $3 \%$ \\
\hline Total & $\begin{array}{c}\mathbf{1 1 7} \\
\text { orang }\end{array}$ & $\mathbf{1 0 0 \%}$ \\
\hline
\end{tabular}

Tabel 7. Jumlah Penghasilan Perbulan

Berdasarkan tabel 7 dapat diketahui bahwa mayoritas penghasilan mahasiswa perantau dalam sebulannya adalah Rp. 500.000 hingga Rp. 1.000 .000 dengan jumlah 56 orang atau sekitar $48 \%$. Kedua terbesar mayoritas penghasilan mahasiswa perantau dalam sebulannya adalah kurang dari Rp. 500.000 dengan jumlah 50 orang atau sekitar $43 \%$.

\begin{tabular}{lcc}
\hline $\begin{array}{c}\text { Sumber } \\
\text { Penghasilan/bulan }\end{array}$ & Jumlah & Presentase \\
\hline Orangtua/ wali & 94 orang & $80 \%$ \\
$\begin{array}{l}\text { Beasiswa instansi } \\
\begin{array}{l}\text { Berkerja / mencari } \\
\text { sendiri }\end{array}\end{array}$ & $\begin{array}{l}13 \text { orang } \\
\text { Suami }\end{array}$ & $11 \%$ \\
\hline Total & $\begin{array}{c}\mathbf{1 1 7} \\
\text { orang }\end{array}$ & $\mathbf{1 0 0 \%}$ \\
\hline
\end{tabular}

Tabel 8. Sumber Penghasilan Perbulan

Berdasarkan tabel 8 dapat diketahui bahwa mayoritas sumber penghasilan mahasiswa perantau dalam sebulannya orangtua/wali dengan jumlah 94 orang atau sekitar $80 \%$.

\begin{tabular}{lll}
\hline \multicolumn{1}{c}{ Tempat Tinggal } & Jumlah & Presentase \\
\hline $\begin{array}{l}\text { Tinggal dengan } \\
\text { orangtua }\end{array}$ & 24 orang & $21 \%$ \\
$\begin{array}{l}\text { Ngekos - asrama } \\
\text { Menumpang }\end{array}$ & $\begin{array}{l}40 \text { orang } \\
\text { Korang }\end{array}$ & $34 \%$ \\
Kontrak rumah & 20 orang & $17 \%$ \\
Tinggal dengan & 26 orang & $22 \%$ \\
keluarga selain & & \\
orangtua & & \\
Mertua & 1 orang & $1 \%$ \\
Marbot masjid & 1 orang & $1 \%$ \\
Tinggal dengan & 1 orang & $1 \%$ \\
orangtua asuh & &
\end{tabular}

\begin{tabular}{lcc}
$\begin{array}{l}\text { Rumah milik } \\
\text { sendiri }\end{array}$ & 1 orang & $1 \%$ \\
\hline Total & $\begin{array}{c}\mathbf{1 1 7} \\
\text { orang }\end{array}$ & $\mathbf{1 0 0 \%}$ \\
\hline Tabel 9. Tempat Tinggal Saat Berkuliah di Kota \\
$\begin{array}{c}\text { Pontianak } \\
\text { Ponal }\end{array}$
\end{tabular}

Berdasarkan tabel 9 dapat diketahui bahwa mayoritas tempat tinggal mahasiswa perantau di Kota Pontianak adalah ngekos atau asrama dengan jumlah 40 orang atau sekitar $34 \%$.

\begin{tabular}{lcc}
\hline \multicolumn{1}{c}{ Domisili Asal } & Jumlah & Presentase \\
\hline $\begin{array}{l}\text { Luar Kota } \\
\begin{array}{l}\text { Pontianak } \\
\text { Luar Kota }\end{array}\end{array}$ & $\begin{array}{c}106 \\
\text { orang }\end{array}$ & $91 \%$ \\
$\begin{array}{l}\text { Kalimantan Barat } \\
\text { Luar Indonesia/ } \\
\text { Luar Negeri }\end{array}$ & 10 orang & $9 \%$ \\
\hline Total & $\begin{array}{c}\mathbf{1 1 7} \\
\text { orang }\end{array}$ & $\mathbf{1 0 0 \%}$ \\
\hline
\end{tabular}

Tabel 10. Domisili Tinggal Sebelum Berkuliah

Berdasarkan tabel 10 dapat diketahui bahwa mayoritas domisili mahasiswa perantau sebelum berkuliah adalah diluar kota Pontianak dengan jumlah 106 orang atau sekitar $91 \%$.

Selanjutnya, untuk mendeskripsikan tingkat resiliensi mahasiswa perantau peneliti melakukan uji validitas dan reliabilitas instrumen yang akan dipergunakan. Hasil ujicoba validitas empirik menggunakan product moment, dari 56 item pernyataan terdapat 27 item butir pernyataan yang tidak valid (gugur) dan 29 item pernyataan yang valid.

Sesuai dengan arahan ahli instrumen, demi keseimbangan proporsi pada butir aspek instrumen maka pada item aspek impluse control butir negatif nomor 38 dihapuskan.

Hasil perhitungan nilai reliabilitas alfa cronbach's menggunakan SPSS 22.0 dari 28 item butir instrumen yang valid nilainya 0,830 . Nilai koefisien reliabilitas tersebut menunjukkan hasil pengukuran instrumen yang digunakan memiliki konsistensi yang 
cukup baik pada setiap responden. Persepsi responden mengenai pernyataan yang digunakan sudah homogen.

Norma kelompok instrumen resiliensi yang dipergunakan pada 118 mahasiswa perantau di BKI IAIN Pontianak adalah sebagai berikut, dinyatakan rendah apabila total skor $<75,038$, dinyatakan sedang apabila total skor bernilai diantara 75,038 hingga 86,306, dan dinyatakan tinggi apabila total skor > 86,306. Berdasarkan norma kelompok tersebut, maka diperoleh hasil kategorisasi tingkat resiliensi mahasiswa perantau di BKI IAIN Pontianak sebagai berikut: 9 orang mahasiswa perantau memiliki tingkat resiliensi yang rendah, 74 orang memiliki tingkat resiliensi yang sedang, dan 35 orang mahasiswa sisanya memiliki tingkat resiliensi yang tinggi.

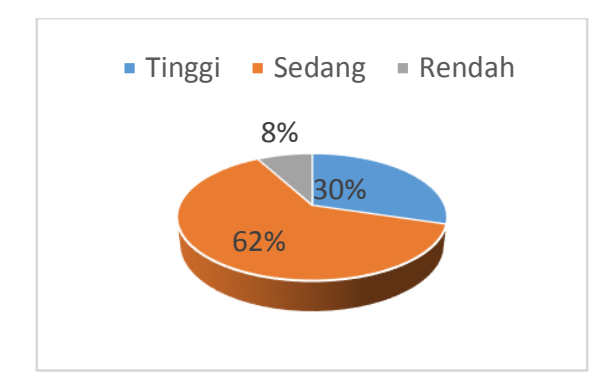

Grafik 1. Presentase Tingkat Resiliensi Mahasiswa Perantau

Berdasarkan grafik 1 presentase tingkat resiliensi diketahui mayoritas $62 \%$ atau 74 orang mahasiswa perantau memiliki tingkat resiliensi sedang. Hanya 35 orang mahasiswa atau 30\% dari keseluruhan mahasiswa perantau yang memiliki tingkat resiliensi yang tinggi. Kategorisasi nilai ini dapat diartikan bahwa mahasiswa yang memiliki tingkat resiliensi tinggi memiliki mekanisme koping yang tepat, efektif dan memiliki adaptasi diri yang positif saat berhadapan dengan stressor yang beresiko tinggi mengalami stress (Hendriyani, 2018). Lebih spesifik instrumen resiliensi oleh peneliti telah dihitung secara per-aspek, diantaranya aspek regulasi emosi, kontrol terhadap implus, optimisme, kemampuan menganalisis masalah, empati, efikasi diri serta pencapaian diri sebagai berikut:

\section{Aspek regulasi diri}

Norma kelompok pada aspek regulasi emosi yang dipergunakan adalah sebagai berikut, dinyatakan rendah apabila total skor $<9,231$, dinyatakan sedang apabila total skor bernilai diantara 9,231 hingga 11,904, dan dinyatakan tinggi apabila total skor > 11,904. Berdasarkan norma kelompok tersebut, maka diperoleh hasil kategorisasi tingkat regulasi emosi mahasiswa perantau di BKI IAIN Pontianak sebagai berikut: 23 orang mahasiswa perantau memiliki tingkat regulasi emosi yang rendah, 73 orang memiliki tingkat regulasi emosi yang sedang, dan 22 orang mahasiswa sisanya memiliki tingkat regulasi emosi yang tinggi.

Data tersebut menunjukkan mayoritas mahasiswa perantau memiliki tingkat regulasi emosi yang sedang atau cukup. Bagi mahasiswa perantau yang memiliki regulasi emosi rendah dapat diartikan oleh Reivich dan Shatté (2002) pada hasil penelitiannya sebagai individu yang kurang mampu dalam mengatur emosi dan mereka akan mengalami kesulitan dalam membangun serta menjaga hubungan dengan orang lain. Sebaliknya bagi mahasiswa perantau yang memiliki regulasi emosi yang tinggi, mereka memiliki kemudahan dalam mengelola respon saat berinteraksi dengan orang lain maupun dalam berbagai kondisi di lingkungan. Regulasi emosi dinilai sangat penting untuk membangun suatu hubungan yang intim, kesuksesan dalam kerja, dan menjaga kesehatan fisik.

\section{Aspek control terhadap implus.}

Selanjutnya, norma kelompok pada aspek kontrol terhadap implus yang dipergunakan pada penelitian ini adalah sebagai berikut, dinyatakan rendah apabila total skor < 15,681, dinyatakan sedang apabila total skor bernilai diantara 15,681 hingga 19,301, dan dinyatakan tinggi apabila total skor >19,301. Berdasarkan norma kelompok tersebut, maka diperoleh hasil kategorisasi tingkat kontrol terhadap implus mahasiswa perantau di BKI IAIN 
Pontianak sebagai berikut: 72 orang mahasiswa perantau memiliki tingkat kontrol terhadap implus yang rendah dan 46 orang memiliki tingkat kontrol terhadap implus yang sedang.

Data tersebut menyimpulkan bahwa mayoritas mahasiswa perantau memiliki tingkat aspek kontrol terhadap implus yang rendah. Menurut Hendriyani (2018) individu yang memiliki kemampuan control terhadap implus yang rendah akan cepat mengalami perubahan emosi ketika berhadapan dengan berbagai situasi dari lingkungan. Individu tersebut akan cenderung reaktif, menampilkan perilaku mudah marah, kehilangan kesabaran, impulsif dan berperilaku agresif. Sehingga membuat orang yang berada di sekitarnya kurang nyaman dan berakibat pada buruknya hubungan sosial individu dengan orang lain.

\section{Aspek optimisme.}

Norma kelompok pada aspek optimisme yang dipergunakan pada penelitian ini adalah sebagai berikut, dinyatakan rendah apabila total skor < 9,959, dinyatakan sedang apabila total skor bernilai diantara 9,959 hingga 13,040, dan dinyatakan tinggi apabila total skor >13,040. Berdasarkan norma kelompok tersebut, maka diperoleh hasil kategorisasi tingkat optimisme mahasiswa perantau di BKI IAIN Pontianak sebagai berikut: 11 orang mahasiswa perantau memiliki tingkat optimisme yang rendah, 94 orang memiliki tingkat optimisme yang sedang, dan 13 orang mahasiswa sisanya memiliki tingkat optimisme yang tinggi.

Dapat disimpulkan dari data tersebut mayoritas mahasiswa perantau memiliki tingkat optimisme yang sedang atau cukup. Menurut Reivich dan Shatté (2002) individu yang optimis mempunyai kemampuan untuk mengatasi kemalangan yang mungkin akan terjadi di masa depan. Optimisme yang dimaksudkan adalah optimisme yang realistis.

\section{Aspek kemampuan menganalisis masalah}

Norma kelompok pada aspek kemampuan menganalisis masalah yang dipergunakan pada penelitian ini adalah sebagai berikut, dinyatakan rendah apabila total skor < 6,318, dinyatakan sedang apabila total skor bernilai diantara 6,318 hingga 8,325 , dan dinyatakan tinggi apabila total skor > 8,325. Berdasarkan norma kelompok tersebut, maka diperoleh hasil kategorisasi tingkat kemampuan menganalisis masalah mahasiswa perantau di BKI IAIN Pontianak sebagai berikut: 19 orang mahasiswa perantau memiliki tingkat kemampuan menganalisis masalah yang rendah, 85 orang memiliki tingkat kemampuan menganalisis masalah yang sedang, dan 14 orang mahasiswa sisanya memiliki tingkat kemampuan menganalisis masalah yang tinggi.

Mayoritas mahasiswa perantau memiliki kemampuan analisis masalah yang sedang atau cukup. Dampak dari individu yang tidak mampu mengidentifikasi penyebab dari permasalahan secara tepat, mereka akan terus-menerus membuat kesalahan yang sama (Reivich \& Shatte, 2002).

\section{Aspek empati}

Norma kelompok pada aspek empati yang dipergunakan pada penelitian ini adalah sebagai berikut, dinyatakan rendah apabila total skor < 10,141, dinyatakan sedang apabila total skor bernilai diantara 10,141 hingga 13,299, dan dinyatakan tinggi apabila total skor $>13,299$. Berdasarkan norma kelompok tersebut, maka diperoleh hasil kategorisasi tingkat empati mahasiswa perantau di BKI IAIN Pontianak sebagai berikut: 25 orang mahasiswa perantau memiliki tingkat empati yang rendah, 77 orang memiliki tingkat empati yang sedang, dan 16 orang mahasiswa sisanya memiliki tingkat empati yang tinggi.

Mayoritas mahasiswa perantau memiliki kemampuan empati yang sedang atau cukup. Menurut Reivich dan Shatté (2002) individu yang memiliki empati dapat menginterpretasikan bahasa-bahasa non verbal yang ditunjukkan orang lain, mampu 
menangkap apa yang dipikirkan dan dirasakan orang lain. Individu tersebut akan mempunyai hubungan sosial yang positif. Sebaliknya, individu yang memiliki kemampuan empati rendah mereka tidak mampu menempatkan diri pada posisi orang lain, tidak merasakan apa yang dirasakan orang lain, dan tidak dapat memperkirakan maksud orang lain. Individu tersebut cenderung menyamaratakan semua keinginan dan emosi orang lain, sehingga berpotensi menimbulkan kesulitan dalam hubungan sosial.

\section{Aspek efikasi diri}

Norma kelompok pada aspek efikasi diri yang dipergunakan pada penelitian ini adalah sebagai berikut, dinyatakan rendah apabila total skor < 7,036, dinyatakan sedang apabila total skor bernilai diantara 7,036 hingga 9,641, dan dinyatakan tinggi apabila total skor >9,641. Berdasarkan norma kelompok tersebut, maka diperoleh hasil kategorisasi tingkat efikasi diri 118 orang mahasiswa perantau di BKI IAIN Pontianak terkategori rendah.

Data diatas menunjukkan bahwa seluruh mahasiswa perantau memiliki efikasi diri yang rendah. Menurut Bandura (1997) dalam teori social kognitifnya menyebutkan rendahnya efikasi diri akan menyebabkan meningkatnya kecemasan dan perilaku menghindar. Individu tersebut akan menghindari aktivitas-aktivitas yang dapat memperburuk keadaan, hal ini bukan disebabkan oleh ancaman tapi karena merasa tidak mempuanyai kemampuan untuk mengelola aspek-aspek berisiko.

\section{Aspek pencapaian diri}

Norma kelompok pada aspek pencapaian diri yang dipergunakan pada penelitian ini adalah sebagai berikut, dinyatakan rendah apabila total skor < 13,036 , dinyatakan sedang apabila total skor bernilai diantara 13,036 hingga 16,726, dan dinyatakan tinggi apabila total skor > 16,726. Berdasarkan norma kelompok tersebut, maka diperoleh hasil kategorisasi tingkat pencapaian diri mahasiswa perantau di BKI IAIN Pontianak sebagai berikut: 30 orang mahasiswa perantau memiliki tingkat pencapaian diri yang rendah, 67 orang memiliki tingkat pencapaian diri yang sedang, dan 21 orang mahasiswa sisanya memiliki tingkat pencapaian diri yang tinggi.

Data tersebut menjelaskan mayoritas mahasiswa perantau memiliki tingkat pencapaian diri yang sedang. Pencapaian diri dalam resiliensi adalah kemampuan individu untuk meraih aspek positif dari kehidupan setelah kemalangan yang menimpa (Reivich dan Shatté, 2002).

Lebih spesifik dapat dilihat perbandingan presentase tingkat per-aspek resiliensi dapat dilihat pada grafik dibawah ini:

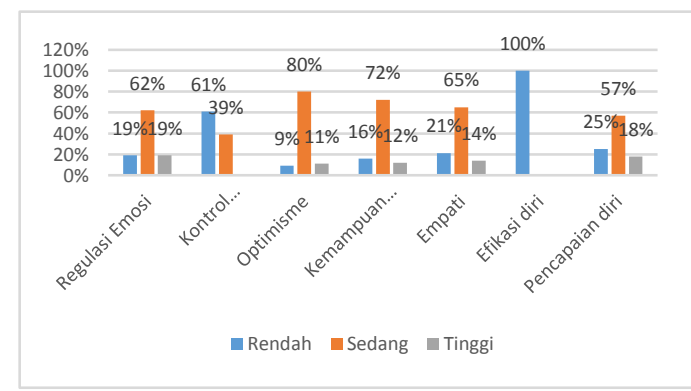

Grafik 2. Presentase Tingkat Aspek Resiliensi Mahasiswa Perantau

Berdasarkan grafik 3 dapat disimpulkan bahwa terdapat dua aspek dengan nilai terendah namun jumlah terbanyak yang dimiliki oleh seluruh mahasiswa perantau yaitu aspek efikasi diri (100\%) dan aspek control terhadap implus (61\%). Hal ini menjadi perhatian khusus oleh peneliti mengingat aspek tersebut memiliki peran penting dari terbentuknya diri resiliensi yang sehat. Aspek regulasi emosi (62\%), aspek optimisme (80\%), aspek kemampuan menganalisis masalah $(72 \%)$, aspek empati $(65 \%)$, dan aspek pencapaian diri $(57 \%)$ masing-masing aspek tersebut memiliki skor yang terkategori sedang.

Selanjutnya, analisis deskriptif tingkat resiliensi mahasiswa perantau berdasarkan kelompok gender, etnis, kelas sosial (pendapatan sebulan), status pernikahan dan 
tingkat tahun angkatan adalah sebagai berikut:

\section{Kelompok gender}

\begin{tabular}{llcl}
\hline \multicolumn{1}{c}{ Gender } & $\begin{array}{c}\text { Tinggi } \\
(>\mathbf{8 6 , 2 7 0 )})\end{array}$ & $\begin{array}{c}\text { Sedang } \\
(\mathbf{7 2 , 8 5 7 -}\end{array}$ & $\begin{array}{c}\text { Rendah } \\
(<72,857)\end{array}$ \\
\hline Perempuan & 15 orang & 62 orang & 13 orang \\
Laki-laki & 3 orang & 18 orang & 6 orang \\
\hline
\end{tabular}

Tabel 10. Tingkat resiliensi berdasarkan kelompok gender

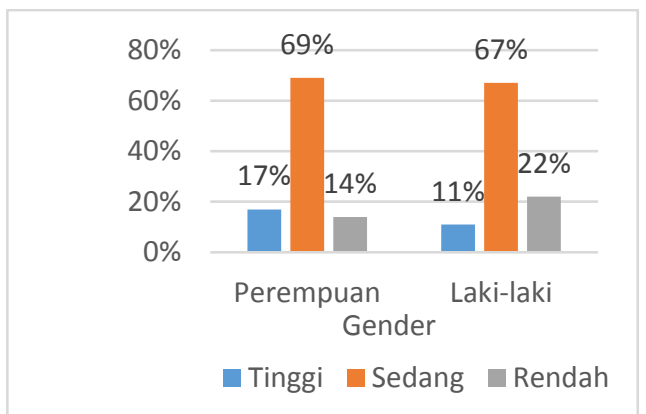

Grafik 3. Tingkat Resiliensi Berdasarkan Gender

Berdasarkan tabel 10 dan grafik 3 dapat diketahui bahwa mayoritas tingkat resiliensi mahasiswa perantau berdasarkan kelompok gender adalah sedang, baik dari gender lakilaki maupun perempuan. Laki-laki berjumlah 18 orang atau sekitar $67 \%$ dan perempuan berjumlah 62 orang atau sekitar $69 \%$.

\section{Kelompok Etnis}

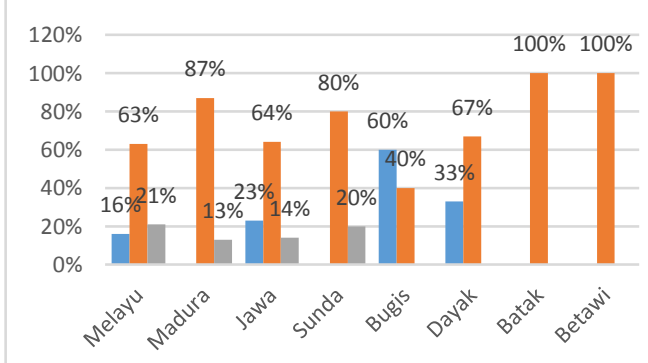

Grafik 4. Tingkat Resiliensi Berdasarkan Etnis

\begin{tabular}{cccc}
\hline Etnis & $\begin{array}{c}\text { Tinggi } \\
(>\mathbf{8 6 , 2 7 0 )}\end{array}$ & $\begin{array}{c}\text { Sedang } \\
(\mathbf{7 2 , 8 5 7 -}\end{array}$ & $\begin{array}{c}\text { Rendah } \\
(<\mathbf{8 6 , 2 7 0})\end{array}$ \\
& & \\
\hline Melayu & 9 orang & 35 orang & 12 orang
\end{tabular}

\begin{tabular}{llll} 
Madura & - & 20 orang & 3 orang \\
Jawa & 5 orang & 14 orang & 3 orang \\
Sunda & - & 4 orang & 1 orang \\
Bugis & 3 orang & 2 orang & - \\
Dayak & 1 orang & 2 orang & - \\
Batak & - & 1 orang & - \\
Betawi & - & 1 orang & - \\
\hline \multicolumn{4}{c}{ Tabel 11. Tingkat resiliensi berdasarkan } \\
\multicolumn{4}{c}{ kelompok etnis }
\end{tabular}

Berdasarkan tabel 11 dan grafik 4 dapat diketahui bahwa mayoritas tingkat resiliensi mahasiswa perantau berdasarkan kelompok etnis adalah sedang, baik dari etnis Melayu, Madura, Jawa, Sunda, Dayak, Batak, dan Betawi. Hanya etnis Bugis yang mayoritas kelompoknya memiliki resiliensi tinggi dari 5 orang sampel mahasiswa perantau 3 diantaranya memiliki tingkat resiliensi yang tinggi.

\section{Kelompok kelas sosial (pendapatan dalam sebulan)}

\begin{tabular}{|c|c|c|c|}
\hline $\begin{array}{c}\text { Pendapatan } \\
\text { dalam } \\
\text { sebulan }\end{array}$ & $\begin{array}{c}\text { Tinggi } \\
(> \\
86,270)\end{array}$ & $\begin{array}{l}\text { Sedang } \\
(\mathbf{7 2 , 8 5 7 -} \\
\mathbf{8 6 , 2 7 0 )}\end{array}$ & $\begin{array}{c}\text { Rendah } \\
(<72,857)\end{array}$ \\
\hline$<$ Rp.500.000 & 7 orang & 36 orang & 7 orang \\
\hline $\begin{array}{l}\text { Rp.500.000 - } \\
\text { Rp.1.000.000 }\end{array}$ & 9 orang & 38 orang & 9 orang \\
\hline $\begin{array}{l}\text { Rp.1.000.000 - } \\
\text { Rp.2.000.000 }\end{array}$ & 1 orang & 3 orang & 3 orang \\
\hline$>$ Rp.2.000.000 & 1 orang & 3 orang & - \\
\hline
\end{tabular}

Tabel 11. Tingkat resiliensi berdasarkan kelompok kelas sosial

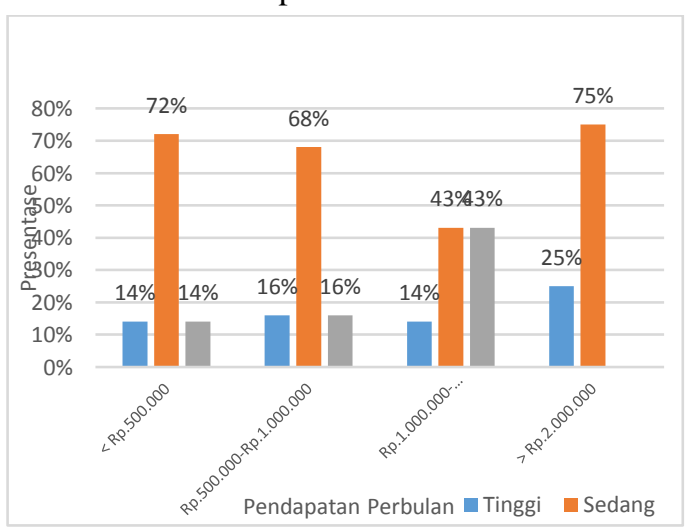

Grafik 5. Tingkat Resiliensi Berdasarkan Kelas Sosial (Pendapatan Perbulan)

Berdasarkan tabel 12 dan grafik 5 dapat diketahui bahwa mayoritas tingkat 
resiliensi mahasiswa perantau berdasarkan kelas sosial adalah sedang. Artinya, 38 dari 117 orang mahasiswa dengan pendapatan perbulan Rp.500.000,- hingga Rp.1.000.000,perbulan memiliki tingkat resiliensi yang sedang, disusul dengan 36 orang mahasiswa dengan pendapatan perbulan kurang dari Rp.500.000,-.

\section{Kelompok status pernikahan}

\begin{tabular}{llll}
\hline \multicolumn{1}{c}{ Status } & Tinggi & Sedang & \multicolumn{1}{c}{ Rendah } \\
Pernikahan & $(>$ & $\mathbf{( 7 2 , 8 5 7 -}$ & \multicolumn{1}{c}{$(<\mathbf{7 2 , 8 5 7 )})$} \\
& $\mathbf{8 6 , 2 7 0 )}$ & $\mathbf{8 6 , 2 7 0 )}$ & \\
\hline Menikah & 1 orang & 7 orang & 1 orang \\
Lajang & 17 orang & 73 orang & 18 orang \\
\hline
\end{tabular}

Tabel 12. Tingkat resiliensi berdasarkan kelompok status pernikahan

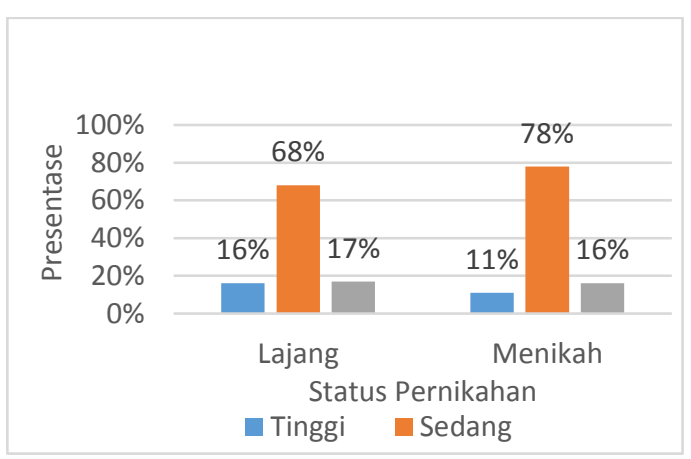

Grafik 6. Tingkat Resiliensi Berdasarkan Status Pernikahan

Berdasarkan tabel 13 dan grafik 6 dapat diketahui bahwa mayoritas tingkat resiliensi mahasiswa perantau berdasarkan kelompok status pernikahan adalah sedang. 78\% mahasiswa perantau yang sudah menikah memiliki tingkat resiliensi sedang dan 68\% mahasiswa perantau yang lajang memiliki tingkat resiliensi sedang. Tidak ada perbedaan yang signifikan.

\section{Kelompok tingkatan tahun angkatan}

\begin{tabular}{|c|c|c|c|}
\hline $\begin{array}{c}\text { Tahun } \\
\text { Angkata } \\
\text { n }\end{array}$ & $\begin{array}{c}\text { Tinggi } \\
(> \\
86,270 \\
)\end{array}$ & $\begin{array}{c}\text { Sedang } \\
(72,857 \\
- \\
86,270)\end{array}$ & $\begin{array}{c}\text { Rendah } \\
(<72,857 \\
)\end{array}$ \\
\hline 2015 & 6 orang & 26 orang & 7 orang \\
\hline
\end{tabular}

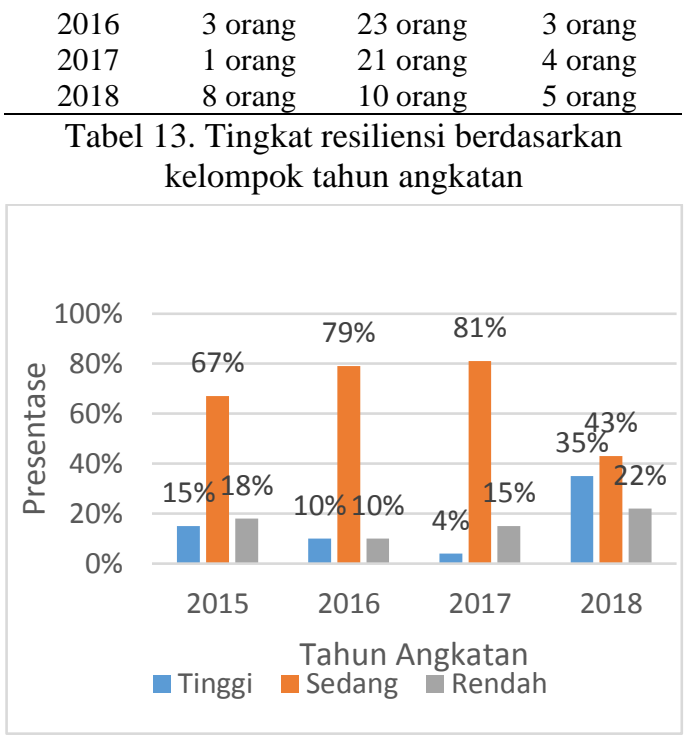

Grafik 7. Tingkat Resiliensi BerdasarkanTahun Angkatan

Berdasarkan tabel 14 dan grafik 7 dapat diketahui bahwa mayoritas tingkat resiliensi mahasiswa perantau berdasarkan kelompok tingkat tahun angkatan adalah sedang.

Penelitian ini akan lebih kaya hasil informasi apabila juga dikaji lebih mendalam dengan menggunakan analisis pendekatan kualitatif. Terlebih diketahui terdapat mahasiswa perantau yang mendapat skor kategori rendah dari 2 aspek resiliensi yaitu aspek efikasi diri dan aspek control terhadap implus.

\section{KESIMPULAN}

Hasil penelitian ini menggambarkan bahwa mayoritas mahasiswa perantau di program studi BKI IAIN Pontianak memiliki tingkat resiliensi yang sedang. Tingkat resiliensi sedang dinyatakan apabila hasil total skor instrumen bernilai diantara 75,038 hingga 86,306, dan sebanyak 74 orang mahasiswa perantau atau sekitar $62 \%$ dari seluruh sampel memiliki nilai total skor diantara rentang nilai kategori tersebut.

Selain itu diketahui dari 7 aspek resiliensi mahasiswa perantau, aspek regulasi emosi, optimisme, kemampuan menganalisis masalah, empati, dan pencapaian diri masing-masing aspek 
memiliki skor yang terkategori sedang. Lebih lanjut hasil penelitian ini menggambarkan bahwa terdapat dua aspek dengan nilai terendah namun jumlah terbanyak yang dimiliki oleh seluruh mahasiswa perantau yaitu aspek efikasi diri (100\%) dan aspek control terhadap implus $(61 \%)$.

Selanjutnya analisis tingkat resiliensi berdasarkan kelompok gender, etnis, kelas sosial (pendapatan sebulan), status pernikahan dan tingkat tahun angkatan tidak ada menunjukkan hasil tingkat perbedaan yang signifikan jauh. Mayoritas pada masing-masing kelompok memiliki tingkat resiliensi yang sedang.

Saran untuk penelitian selanjutnya adalah akan sangat baik apabila penelitian studi deskriptif ini dikembangkan dengan penelitian kualitatif. Serta pengembangan penelitian kuantitatif dengan populasi sampel penelitian menjadi seluruh mahasiswa perantau di perguruan tinggi sekota Pontianak yang memiliki program jurusan bimbingan konseling.

\section{DAFTAR PUSTAKA}

Alisjahbana, A., Sidharta, M., \& Brouwer, M. . (1983). Menuju Kesejahteraan Jiwa. Jakarta: Gramedia.

Amaliya, R. (2019). Faktor-Faktor Yang Mempengaruhi Keputusan Mahasiswa Memilih Pendidikan Pada Program Studi Pendidikan Ekonomi FE UNY. Jurnal Pendidikan Dan Ekonomi: Kajian Ilmiah Bidang Pendidikan Dan Ekonomi, 8(1), 34-43.

Dörnyei, Z. (2007). Research methods in applied linguistics. New York: Oxford University Press.

Grotberg, E. (1995). A guide to promoting resilience in children: strengthening the human spirit, Early Childhood Development: Practice and Reflections Number 8. Bernard van Leer Foundation.

Havighurst, R. J. (1961). Successful Aging1. The Gerontologist, 1(1), 8-13. https://doi.org/10.1093/geront/1.1.8
Hendriani, W. (2018). Resiliensi Psikologis: Sebuah Pengantar. Jakarta: Prenada Media Group.

Indriyanti, N., Siswandari, \& Ivada, E. (2013). Faktor-Faktor Yang Memengaruhi Minat Melanjutkan Pendidikan Ke Perguruan Tinggi Pada Siswa Kelas XII Akuntansi Smk Negeri 6 Surakarta Tahun 2013. Jupe-Jurnal Pendidikan Ekonomi, 1(2), 1-10.

Kementerian Riset dan Teknologi Nasional. (2018). Kemenristekdikti Umumkan Peringkat 100 Besar Perguruan Tinggi Indonesia Non Vokasi Tahun 2018. Retrieved from https://www.ristekbrin.go.id/kabar/kem enristekdikti-umumkan-peringkat-100besar-perguruan-tinggi-indonesia-nonvokasi-tahun-2018/

Reivich, K., \& Shatte, A. (2002). The resilience factor: 7 essential skills for overcoming life's inevitable obstacles. Broadway, Portland: Broadway Books.

Tempo.co. (2017). SBMPTN, Survei Tempo Ihwal 12 Fakultas Favorit PTN dan PTS. Retrieved from https://nasional.tempo.co/read/864692/s bmptn-survei-tempo-ihwal-12-fakultasfavorit-ptn-dan-pts

Widhiarso, W. (2010). Membuat kategori skor hasil pengukuran dari skala. Yogyakarta: Universitas Gadjah Mada.

Wosnitza, M., Delzepich, R., Schwarze, J., O'Donnell, M., Faust, V., \& Camilleri, V. (2018). Enhancing teacher resilience: From Self-Reflection to professional development. In M. Wosnitza, F. Peixoto, S. Beltman, \& C. Mansfield (Eds.), Resilience in Education (pp. 275-288). Cham: Springer.

Yeager, D. S., \& Dweck, C. S. (2012). Mindsets That Promote Resilience: When Students Believe That Personal Characteristics Can Be Developed. Educational Psychologist, 47(4), 302314. https://doi.org/10.1080/00461520.2012. 722805

Yusuf, S. (2012). Psikologi Perkembangan Anak dan Remaja. Bandung: Remaja Rosdakarya. 